\title{
Suppression of oocyte release in rats by local administration of the noradrenergic neurotoxin DSP4
}

\author{
J. M. Goldman, T. E. Stoker, R. L. Cooper, W. K. McElroy and \\ M. B. Parrish \\ Endocrinology Branch, Reproductive Toxicology Division, National Health and Environmental Effects \\ Research Laboratory, US Environmental Protection Agency, Research Triangle Park, NC 27711, USA
}

\begin{abstract}
The presence of noradrenergic neuronal innervation in the ovaries and cyclic alterations in ovarian noradrenaline suggest a role for such innervation in oocyte release. The current experiments evaluated the relationship between ovulation and alterations in ovarian concentrations of noradrenaline induced by unilateral, intrabursal administration of the specific noradrenergic neurotoxin DSP4. Intrabursal injections of DSP4 $(0-10 \mu$ moles per ovary) given at 19:00 $\mathrm{h}$ at pro-oestrus induced a prompt, dose-related reduction in ovarian noradrenaline on the injected and non-injected sides. Although this result suggests that injected material was reaching the contralateral ovary, ovulation was suppressed only on the injected side. This suppression was persistent, and lasted through at least the next two cycles following either unilateral or bilateral treatment. The reductions in noradrenaline could be mostly, if not entirely, attenuated by prior administration of desipramine which blocks re-uptake of noradrenaline, while the ipsilateral ovulatory effects remained unchanged. Although it has been reported that DSP 4 binds the opiate receptor, intrabursal co-administration of the antagonist naloxone was ineffective in altering ovulatory suppression. These results suggest that while decreases in ovarian noradrenaline in response to local exposure to a noradrenergic neurotoxin may accompany a reduction in oocyte release or a block in ovulation, the anti-ovulatory effect of DSP4 is independent of the changes in noradrenaline concentrations and may be due to some other ovarian response.
\end{abstract}

\section{Introduction}

It has been known for some time that regulation of the cyclic pattern of ovulation in female mammals involves the participation of noradrenergic neurotransmitter mechanisms. In the hypothalamus, such neurotransmitter activity is a critical component of the sequence of events leading to the generation of the ovulatory surge of LH. Perturbations in this hypothalamic activity can suppress the midcycle increase in $\mathrm{LH}$ and block ovulation (Everett and Sawyer, 1950; Kalra and McCann, 1974; Goldman et al., 1994). However, noradrenergic neuronal innervation is also present in the ovaries, suggesting that an alteration in noradrenergic activity by systemic xenobiotic exposure could affect the process of ovulation, not only by suppressing the LH surge, but also through a direct influence on the ovaries.

In mammals, noradrenergic sympathetic input reaches the ovary via the superior ovarian nerve and the nerves of the ovarian plexus that accompany the ovarian artery. In addition to this vascular innervation, catecholaminergic terminals have been identified histochemically within the stroma and follicular wall (Jacobowitz and Wallach, 1967). There is evidence that this innervation is involved in the process of follicular matura-

Received 2 August 1995. tion and ovulation, although the precise nature of this participation has not been completely characterized. In prepubertal rats, peripheral noradrenergic depletion by multiple intraperitoneal injections of the adrenergic neurone blocking agent guanethidine delays vaginal opening and increases the number of oocytes detected at first ovulation (Flores et al., 1990). A morphometric analysis of the ovaries from juveniles receiving guanethidine for 3 weeks beginning on day 7 after birth revealed a retardation of follicular development (Lara et al., 1990). These experiments also showed that gonadotrophin stimulation of progesterone and oestrogen secretion in vitro was also reduced. Complementary work in adult rats demonstrated that bilateral injections of the adrenergic neurotoxicant 6-hydroxydopamine under the ovarian bursa induced a chemical sympathectomy that caused an initial disruption to the oestrous cycle and an increase in the appearance of large atretic follicles (Curry et al., 1984).

The purpose of the present study was to extend further the evidence for participation of such adrenergic mechanisms in the ovulatory process and to characterize those changes in the concentration of ovarian noradrenaline that could contribute to identifiable alterations in oocyte release. Normally cyclic, adult rats were given unilateral intrabursal injections of the noradrenergic neurotoxin $\mathrm{N}$-(2-chloro-ethyl)- $\mathrm{N}$-ethyl-2bromobenzylamine (DSP4). This tertiary haloalkylamine 
derivative is both effective as a long-lasting inhibitor of the re-uptake of noradrenaline (Ross, 1973; Dudley et al., 1990) and can block the synthesis of noradrenaline by suppressing the activity of dopamine- $\beta$-hydroxylase (Ross, 1976). However, unlike 6-hydroxydopamine, these effects do not appear to be accompanied by nonspecific cellular damage (Dudley et al., 1990) or to cause alterations in dopamine (Ross, 1976; Lookingland et al., 1986), the neurotransmitter that also serves as a metabolic precursor to noradrenaline. Preliminary work in our laboratory showed that DSP4, given either systemically as a single dose or by intrabursal injection, could induce a prompt and marked decline in ovarian noradrenaline, suggesting its suitability for investigations of this nature.

\section{Materials and Methods}

\section{Animals}

Ninety-day-old, female Long-Evans hooded rats were obtained from Charles River Laboratories (Raleigh, NC) and maintained under a photoperiod of $14 \mathrm{~h}$ light:10 $\mathrm{h}$ dark (midnight corresponding to the midpoint of darkness) at $22 \pm 2^{\circ} \mathrm{C}$ with food and water available ad libitum. Oestrous cycles were monitored daily by vaginal lavage, and only those animals between 4 and 5 months of age exhibiting at least three consecutive 4 day cycles immediately before experimentation were used.

\section{Experiment 1}

Experiment I established the effects of intrabursal DSP4 administration on ovarian concentrations of noradrenaline and determined whether any such alterations, if present, were confined to the site of injection or were additionally detectable elsewhere within the reproductive system. This is particularly important since studies using unilateral intrabursal injections have often used the uninjected or vehicle-injected ovary as a control (see Viggiano et al., 1989; Bicsak et al., 1991), even though there is evidence in rats for a small slit-like bursal opening to the peritoneal cavity located near the fimbriated tip of the oviduct (Alden, 1942). Although this foramen was reported to be functionally closed before ovulation (Alden, 1942), its presence may explain contralateral alterations observed following such intrabursal administration (Reich et al., 1983).

The animals were anaesthetized with Brevital ${ }^{10}$ (Eli Lilly, IN; $60 \mathrm{mg} \mathrm{kg}^{-1}$ ) and the dorsolateral flanks shaved. Ovaries were exteriorized through a small incision made in the dorsolateral flank, taking care not to damage the suspensory ligament. Various amounts $(0,2.5$ or $10 \mu$ moles in $10 \mu$ sterile water) of DSP4 (Sigma Chemical Co., St Louis, MO) were then unilaterally injected beneath the ovarian fat pads into randomly chosen left or right bursa using a $50 \mu \mathrm{l}$ gas-tight syringe (Hamilton Co., Reno, NV) with an attached 30 gauge needle. The doses chosen were based upon preliminary experiments with the compound. With the needle in place, a small region of the surrounding bursa was gently pinched to the shaft with fine serrated forceps during both the injection itself and withdrawal of the needle. The injection site was then closed with a drop of rapidly sealing cyanomethacrylate surgical adhesive (Nexaband S/C ${ }^{\mathrm{R}}$; Tri-Point Medical L.P., Raleigh, NC). In preliminary studies this treatment prevented back leakage of a solution of trypan blue. The ovary was carefully returned to the peritoneal cavity, and the abdominal wall and overlying skin were sutured.

A possible suppressive effect of DSP4 on the midcycle surge of LH from the pituitary into the circulation (either directly via passage out from the bursal cavity or indirectly via an alteration in hormonal feedback to the brain or pituitary) was precluded by giving intrabursal injections at 19:00 h on the day of vaginal pro-oestrus, just after the appearance of the surge (which under the above photoperiod begins between 15:00 and 17:00 h (Goldman and Cooper, 1993)). Groups of animals were also given (19:00 h) i.p. or intracardiac injections to compare the effects of systemic exposure to DSP4 on ovulation and concentrations of noradrenaline in tissue. Between 14:00 and 15:00 h on the day of oestrus, the animals were killed by decapitation in an adjoining room within $15 \mathrm{~s}$ of removal from their home cages. Both ovaries were removed, trimmed of fat, and frozen $\left(-55^{\circ} \mathrm{C}\right)$ until used.

Any possible effects of such intrabursal administration on hypothalamic noradrenaline were also evaluated, although the responsiveness of this area to DSP4 is minimal (Grzanna et al., 1989; Zaczek et al., 1990), and any such effects, if present, would have had no impact on the hypothalamic-pituitary mechanisms triggering the earlier ovulatory surge of LH. For this evaluation, rats received intrabursal injections (10 $\mu$ moles per ovary) as above and were killed 1, 3, 7 or $19 \mathrm{~h}$ later. Anterior and posterior hypothalamic regions were dissected and frozen as described previously (Goldman et al., 1994). Seven hours after the injection, portions of the somatosensory cortex were also taken for analysis, since cerebrocortical noradrenaline concentrations are affected markedly by systemic DSP4 administration (Jonsson et al., 1981; Lookingland et al., 1986).

Noradrenaline determinations. Tissue concentrations of noradrenaline were determined by HPLC. Upon thawing, the ovaries were weighed and quickly diced and sonicated over ice as a 1:11 dilution in cold HPLC mobile phase ( $\mathrm{pH}$ 3.1) consisting of $115 \mathrm{mmol}$ dibasic sodium phosphate $\mathrm{I}^{-1}$ (Fisher Chemical, Fairlawn, NJ), 0.19 mmol EDTA $1^{-1}$ (Mallinckrodt, Paris, KY), $3 \mathrm{mmol}$ 1-heptanesulfonic acid $\mathrm{1}^{-1}$, sodium salt (Eastman Kodak, Rochester, NY), and 9\% (v/v) acetonitrile (Burdick \& Jackson, Muskegon, MI) in HPLC grade water previously filtered and deionized through a Milli-Q system (Millipore, Marlborough, MA). Hypothalamic fragments were also diluted and sonicated as above. After removing a $10 \mu \mathrm{l}$ aliquot for total protein analysis, all samples were then centrifuged ( $10 \mathrm{~min}, 8500 \mathrm{~g}, 4^{\circ} \mathrm{C}$ ) before supernatants were drawn off and filtered (Gelman Acrodisc LC13, $0.2 \mu \mathrm{m}$, Ann Arbor, MI). Hypothalamic samples were subsequently diluted 1:2.5 for HPLC injection, while ovarian supernatants were used without further dilution. The HPLC-electrochemical detection system used was as described by Goldman et al. (1994), and a flow rate of $1.5 \mathrm{ml} \mathrm{min}{ }^{-1}$ was used for all separations. Noradrenaline, dopamine, adrenaline and 3,4-dihydroxy-phenylacetic acid (DOPAC) standards for calibration were obtained from Sigma Chemicals. 
Total protein for each sample was measured by the bicinchoninic acid assay (Smith et al, 1985). Materials were obtained from Pierce Chemical (Rockford, IL), and the assay was conducted on a Thermomax microplate reader (Molecular Devices, Menlo Park, CA). Preliminary standardization showed no interference in this procedure by catecholamines at the detected hypothalamic concentrations.

\section{Experiment 2}

Experiment 2 was designed to establish dose- and timeresponse relationships for the influence of DSP4 on ovarian noradrenaline and also to evaluate the impact of exposure to DSP4 on oocyte release at pro-oestrus.

Regularly cyclic females were given unilateral intrabursal injections as above at pro-oestrus, in doses ranging from 0 to $10 \mu$ moles per ovary (in $10 \mu \mathrm{l}$ sterile water). Rats were killed by decapitation on the following day (14:00-15:00 h, oestrus), and ovaries were removed and trimmed of fat before they were frozen for subsequent noradrenaline determinations. Noradrenaline assays were also conducted on previously frozen ovaries taken from those rats described in Expt 1 that were killed at $\mathrm{I}, 3$, or $7 \mathrm{~h}$ after injection, with the $7 \mathrm{~h}$ sample selected to fall during the approximate period of ovulation (see, PlasRoser et al., 1985). Other rats received intrabursal injections (unilateral, 19:00 h pro-oestrus) of $10 \mu$ moles DSP4 per ovary and were examined for evidence of ovulation on vaginal oestrus on either of the next two cycles (that is, 5 or 9 days later) to evaluate a more persistent effect of administration. Other females were bilaterally injected with 0 or $2.5 \mu$ moles DSP 4 per ovary and evaluated for oocyte release 1 or 9 days later.

Oocytes were collected (14:00-15:00 h) and quantified according to procedures described by Perreault and Mattson (1993). Briefly, the oviduct was dissected from the ovary and a cut made at its junction with the uterus. Under a dissecting microscope, the ampulla was flushed with $200 \mu \mathrm{l}$ of Dulbecco's PBS (Gibco, Gaithersburg, MD) containing 0.1\% (w/v) BSA (fraction V, Sigma Chemical) using a $1 \mathrm{ml}$ syringe with attached 30 gauge blunt needle inserted into the infundibulum. The cumulus mass was extruded from the cut end of the oviduct, and individual cumulus-encased oocytes were counted.

\section{Experiment 3}

The relationship between DSP4-induced shifts in ovarian noradrenaline and alterations in ovulation were investigated further by pretreating rats at pro-oestrus with i.p. injections (20 $\mathrm{mg} \mathrm{kg}^{-1}$ body mass) of the noradrenaline reuptake inhibitor desipramine (desmethylimipramine $\mathrm{HCl}$; Sigma Chemical Co.) $1 \mathrm{~h}$ before $(18: 00 \mathrm{~h})$ the unilateral intrabursal injection of DSP4 $(0,1.25$ or $10 \mu$ moles per ovary). Such prior administration interferes with the access of DSP4 to the cell and prevents, at least partially, the depletion of noradrenaline (Ross, 1976; Jonsson $e t$ al., 1982). These animals were killed as before (14:00-15:00 h, oestrus). Ovaries were taken for determinations of noradrenaline, and the oviducts were examined for evidence of ovulation.

In addition to its effect on the uptake of noradrenaline, DSP4 competes for opiate-binding sites in the brain (Wilkinson et al.,
1985). While an opioid role in ovarian function is unclear, ovaries of a variety of species, including rats, contain immunoreactive opioid peptides and their precursors (Lolait et al., 1985; Douglass et al., 1987). Consequently, we attempted to evaluate the ovulatory effect of co-administration of the opiate-receptor antagonist naloxone with DSP4 injected intrabursally.

At 19:00 h on the day of pro-oestrus, regularly cyclic females were given unilateral, intrabursal, injections of $2.5 \mu$ moles DSP4, $8 \mu$ moles naloxone (Sigma Chemical Co.) or $2.5 \mu$ moles DSP4 plus $8 \mu$ moles naloxone. Ten microlitres of sterile, distilled water was used as the injection vehicle, and the procedure was as detailed for Expt 1. Between 14:00 and 15:00 $\mathrm{h}$ on the following day, the oviducts were flushed as above and examined for evidence of ovulation.

\section{Statistical analyses}

Differences in noradrenaline concentrations and numbers of oocytes among dose groups were analysed for statistical significance by analysis of variance (ANOVA) under the General Linear Models (GLM) procedure of the Statistical Analysis System (SAS, Cary, NC) package. Significant main effects of treatment $(P<0.05)$ were subjected to further analysis using Tukey's test for multiple comparisons. For evaluation of treatment effects on the incidence of ovulation, dose groups were compared against controls using the Fisher exact test of probability.

\section{Results}

\section{Experiment 1}

The ovarian concentrations of noradrenaline $18-19 \mathrm{~h}$ after the pro-oestrous injection of 2.5 or $10 \mu$ moles DSP 4 are shown in Table 1. A marked fall in the concentrations of noradrenaline in injected and non-injected ovaries occurred. Although the mean magnitude of the decrease for the injected side in the $2.5 \mu$ moles group (approximately 13\% of the vehicle-injected controls) was somewhat larger than that for the non-injected ovary (approximately $28 \%$ of controls), the difference was not statistically significant. Administration of DSP4 by i.p. or intracardiac injection (Table 1) also resulted in a large fall in noradrenaline concentrations, although the fall was not as large as those caused by the intrabursal injections of DSP4.

Samples of anterior and posterior hypothalamic tissue taken $0,1,3,7$ or $19 \mathrm{~h}$ after injections showed no changes in the concentrations of noradrenaline in response to the intrabursal administration of $10 \mu$ moles DSP 4 per ovary, a normal $\mathrm{pH}$ dose, shown in pilot experiments to cause the maximum depletion in ovarian noradrenaline by $19 \mathrm{~h}$. Over this period, mean values ( \pm SEM) were $20.7 \pm 0.9$ and $15.3 \pm 0.4 \mathrm{ng} \mathrm{mg}^{-1}$ protein for control anterior and posterior regions, respectively, and $21.4 \pm 1.1$ and $15.0 \pm 0.4 \mathrm{ng} \mathrm{mg}^{-1}$ protein for these two regions in animals receiving the $10 \mu$ mole dose. However, measures of cerebrocortical noradrenaline from tissue samples obtained $7 \mathrm{~h}$ after the injection did reveal a small but statistically significant $(P<0.05)$ fall $\left(2.1 \pm 0.4 \mathrm{ng} \mathrm{mg}^{-1}\right.$ protein versus control concentrations of $3.1 \pm 0.1 \mathrm{ng} \mathrm{mg}^{-1}$ ). 
Table 1. Alterations in ovarian concentrations of noradrenaline in rats $19 \mathrm{~h}$ after unilateral intrabursal or systemic administration of DSP4

\begin{tabular}{|c|c|c|c|c|}
\hline 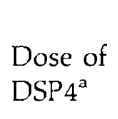 & Route & Ovary & $n$ & $\begin{array}{c}\text { Ovarian } \\
\text { noradrenaline } \\
\text { (ng } \mathrm{mg}^{-1} \text { protein) }\end{array}$ \\
\hline \multirow[t]{2}{*}{0} & Intrabursal & Injected & 6 & $3.79 \pm 0.40$ \\
\hline & & Non-injected & 6 & $3.93 \pm 0.66$ \\
\hline \multirow[t]{2}{*}{2.5} & Intrabursal & Injected & 5 & $0.57 \pm 0.07^{*}$ \\
\hline & & Non-injected & 5 & $1.04 \pm 0.08^{*}$ \\
\hline \multirow[t]{2}{*}{10} & Intrabursal & Injected & 7 & $0.58 \pm 0.11^{*}$ \\
\hline & & Non-injected & 7 & $0.64 \pm 0.09^{*}$ \\
\hline 2.5 & Intraperitoneal & Left and right combined & 6 & $1.70 \pm 0.34^{*}$ \\
\hline 10 & Intraperitoneal & Left and right combined & 5 & $1.82 \pm 0.36^{*}$ \\
\hline 2.5 & Intracardial & Left and right combined & 6 & $1.40 \pm 0.29^{*}$ \\
\hline
\end{tabular}

${ }^{a}$ Doses for intrabursal treatments are in $\mu$ moles per ovary, while those for intraperitoneal and intracardial routes are in $\mu$ moles per rat. ${ }^{*} P<0.01$ for comparisons against the 0 dose treatment for that ovary (intraperitoneal and intracardial treatments were compared against values for the intrabursal control ovaries).

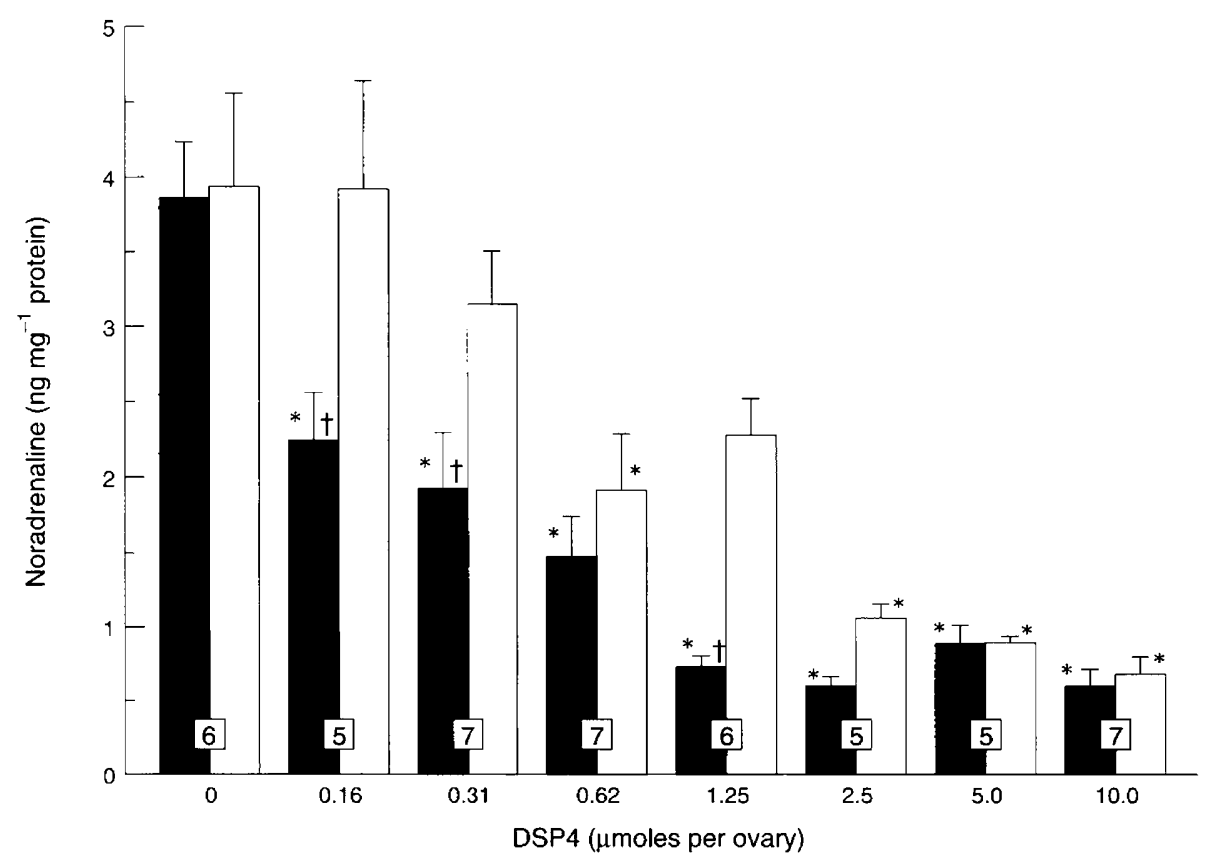

Fig. 1. Dose-response effect of unilateral intrabursal DSP4 administration on ovarian noradrenaline concentrations in rats. All rats were injected at 19:00 h at pro-oestrus, and injected and non-injected ovaries were removed $19 \mathrm{~h}$ later. Group sizes are indicated at the base of each treatment category. ( $\boldsymbol{\square}$ Injected ovaries; ( $\square$ ) non-injected ovaries. ${ }^{*} P<0.01$ for comparisons against control for that ovary; ${ }^{\dagger} P<0.01$ for comparisons against the non-injected ovary within that dose group.

\section{Experiment 2}

The effects of increasing doses of intrabursally administered DSP4 on ovarian noradrenaline are shown for injected and non-injected ovaries (Fig. 1). A clear, dose-related decline was seen for both ovaries at $19 \mathrm{~h}$, with treatments as low as $0.16 \mu$ moles per ovary causing a significant depletion on the injected side. Differences between the two ovaries (with one exception, evident up to a dose of $1.25 \mu$ moles per ovary) were no longer present as noradrenaline concentrations decreased further in response to $2.5,5$ and $10 \mu$ moles DSP4. The fall in ovarian noradrenaline over this period in response to $10 \mu$ moles DSP4 (the dose which at $19 \mathrm{~h}$ induced maximum depletion of noradrenaline) is shown (Fig. 2). Both ovaries showed relatively rapid depletions, such that by $3 \mathrm{~h}$ values were approximately $66 \%$ of $\mathrm{O}$ h values.

The number of oocytes and the percentage of ovaries showing evidence of ovulation (release of either identifiable cumulus-encased oocytes or cumulus only) also showed a dose-related decline in response to 0.62 and $10 \mu$ moles DSP 4 per ovary (Fig. 3). However, this effect was observed only for 


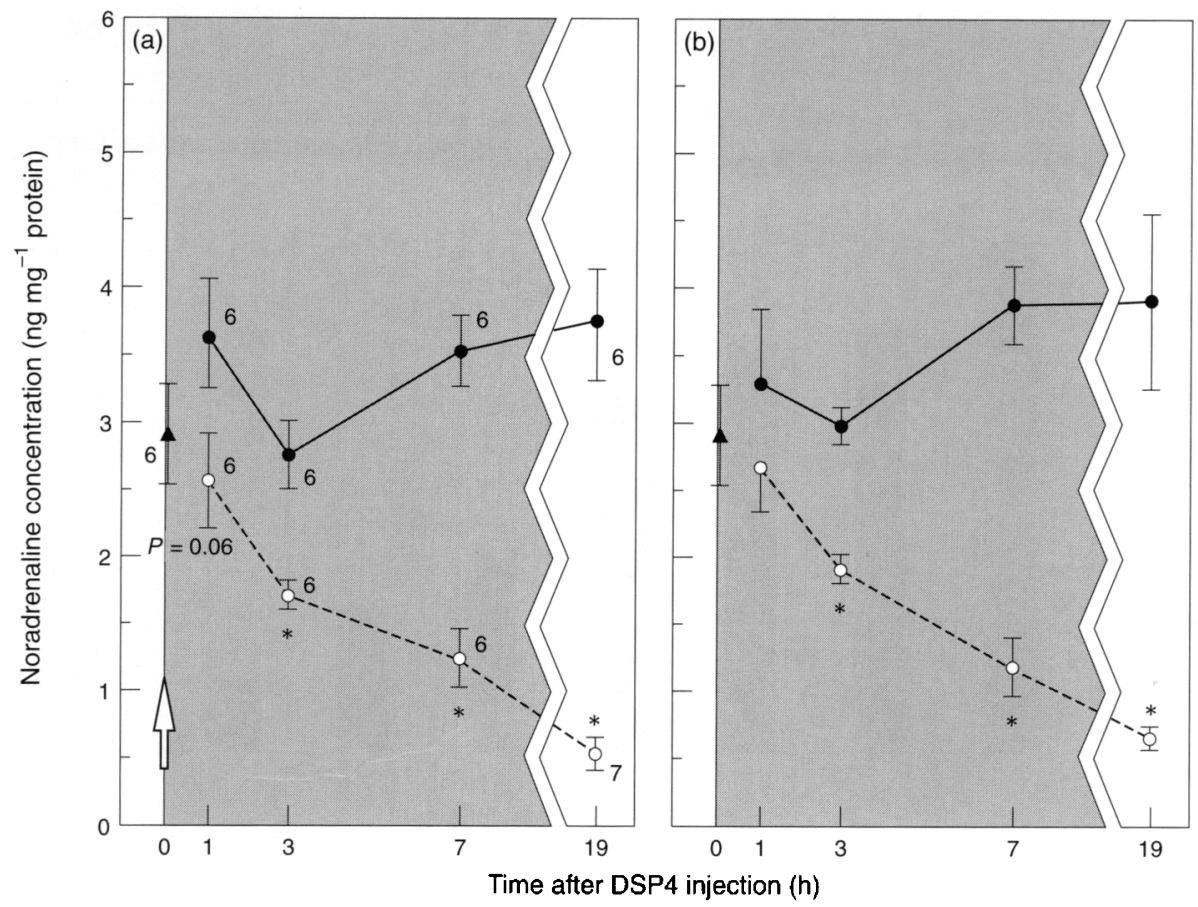

Fig. 2. Changes in ovarian concentrations of noradrenaline (mean \pm SEM) after unilateral intrabursal administration of $10 \mu$ moles DSP4 per ovary. Animals were injected at 19:00 h (arrow) in pro-oestrus. (a) Injected ovary; (b) non-injected ovary. The shaded areas represent the dark portion of the photoperiod. Group sizes are given in (a) at each time point. (- - Vehicle controls; $(--0--)$ DSP4-treated. ( 4 Combined values for pairs of ovaries in non-injected animals at time 0 h. ${ }^{*} P<0.01$ for comparisons against controls at that time point.

the injected ovaries; the non-injected side released a full complement of oocytes throughout the dose range. At the $10 \mu$ moles DSP4 dose, this block persisted through at least the next two ovulatory cycles (Table 2), with these rats showing progressive evidence of a compensatory increase in oocyte release on the contralateral side. This persistence was also evident after bilateral injections of $2.5 \mu$ moles DSP4 per ovary (Table 3), and the reduction in the number of oocytes collected on the day after DSP4 administration did not show any evidence of further decline by the third oestrous day. With two exceptions (that were excluded from the results), the bilaterally injected DSP4 animals continued to display normal patterns of vaginal cytology (as did the controls). Those animals that showed evidence of ovulation, when examined at I or 9 days after treatment, generally ovulated from only one ovary (that is, five of six rats had oocytes only on a single side).

\section{Experiment 3}

The marked depletions in noradrenaline seen in the injected ovaries for both the 1.25 and $10 \mu$ moles DSP 4 groups were at least partially prevented by prior administration of desipramine (Table 4). In the case of the $1.25 \mu$ moles DSP 4 group, pretreatment with desipramine represents a $37 \%$ difference in ovarian noradrenaline (obtained by comparing a $60 \%$ decrease in desipramine plus DSP4 with the marked decline to $23 \%$ for DSP4 exposure only). In contrast, the non-injected ovaries for this same dose of DSP4 displayed a relatively small improve- ment (ovarian noradrenaline values were $69 \%$ that of controls after pretreatment with desipramine compared with $56 \%$ in its absence). Treatment with $10 \mu$ moles DSP 4 per ovary caused reductions to values that for both ovaries at $19 \mathrm{~h}$ were $23 \%$ of control values. Prior administration of desipramine resulted in values for noradrenaline that were $44 \%$ and $78 \%$ of control values for injected and non-injected ovaries, respectively. In the injected ovaries, this reduction in the effect of DSP4 on ovarian noradrenaline in response to desipramine was not associated with a corresponding increase in the number of oocytes released or in the percentage of rats ovulating (Table 4). Although a small improvement in the $1.25 \mu$ moles DSP 4 group was seen in the ratio of ovulating ovaries to the total number examined for that group (in parentheses on the right-hand side of the table), it was not statistically significant.

Co-injections of the opiate receptor antagonist naloxone did not cause any detectable alterations in the effect of $2.5 \mu$ moles DSP4 on the incidence of ovulation or the number of oocytes released (Table 5). Data obtained following the intrabursal administration of naloxone alone were comparable to those from vehicle-injected controls.

\section{Discussion}

The present study was designed to investigate alterations in ovarian concentrations of noradrenaline caused by local, latepro-oestrous injections of the noradrenergic neurotoxin DSP4 


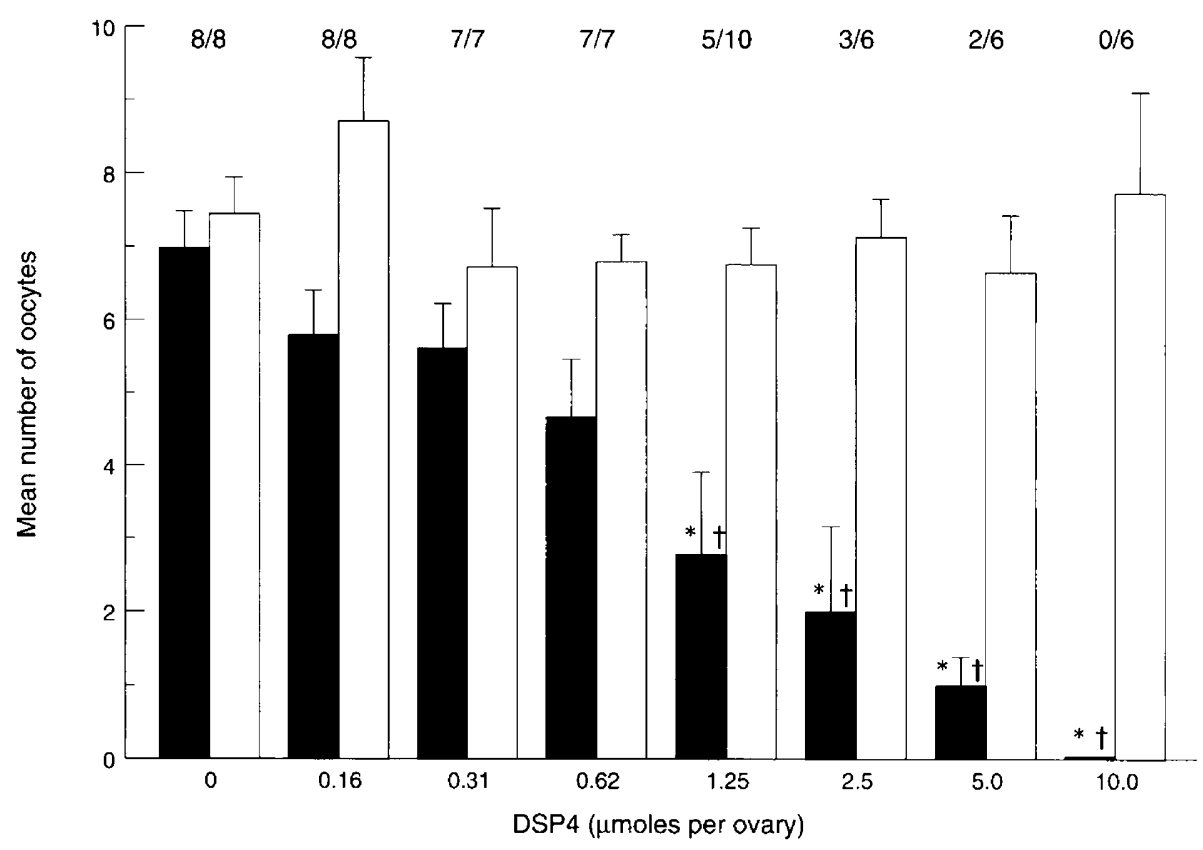

Fig. 3. Alterations in ovulation induced in rats after a unilateral intrabursal injection of DSP4. All animals were injected in pro-oestrus and killed $19 \mathrm{~h}$ later at oestrus. Mean numbers of oocytes for ovulating rats only are represented for $(\boldsymbol{\square})$ injected and $(\square)$ non-injected ovaries; the numbers of ovulating females/group size are listed above each treatment condition. ${ }^{*} p<0.01$ for comparisons against the control treatment for that ovary; ${ }^{\dagger} P<0.05$ for comparisons against the non-injected ovary within that dose group.

Table 2. Oocyte release in cyclic rats after intrabursal injection of $10 \mu$ moles DSP4 per ovary

\begin{tabular}{lcr}
\hline $\begin{array}{l}\text { Time of oocyte } \\
\text { retrieval (days } \\
\text { after injection) }\end{array}$ & $\begin{array}{c}\text { Injected } \\
\text { ovary }\end{array}$ & $\begin{array}{c}\text { Non-injected } \\
\text { ovary }\end{array}$ \\
\hline 1 & $-(0 / 6)$ & $7.8 \pm 1.4(6 / 6)$ \\
5 & $1(1 / 6)$ & $10.0 \pm 0.9(6 / 6)$ \\
9 & $-(0 / 5)$ & $11.6 \pm 0.7(5 / 5)$ \\
\hline
\end{tabular}

Mean number of oocytes ( \pm SEM) represent only individual ovaries showing evidence of ovulation. The numbers in parentheses represent the number of ovaries ovulating divided by the total number of rats within that group displaying 4 day cycles after treatment.

and the relationship of such changes to oocyte release. Unilateral intrabursal injections were found to induce dose-related depletions of noradrenaline in the injected ovary and in areas peripheral to the site of administration. Sealing the injection site with a veterinary surgical adhesive did not prevent reductions in noradrenaline values in the contralateral ovary or in cerebrocortical noradrenaline. These results indicate that DSP4 was not confined to the sub-bursal space, and are consistent with the similar magnitude of alterations in ovarian noradrenaline seen in groups receiving DSP4 by intrabursal or systemic (that is, i.p. or intracardial) routes of administration. It is also in agreement with the extra-ovarian distribution of an intrabursal injection of $\left[{ }^{3} \mathrm{H}\right]$ thymidine (J. M. Goldman, unpublished observations) and with previously reported biochemical
Table 3. Persistence of the effects of a bilateral pro-oestrous injection of DSP4 on ovulation in cyclic rats

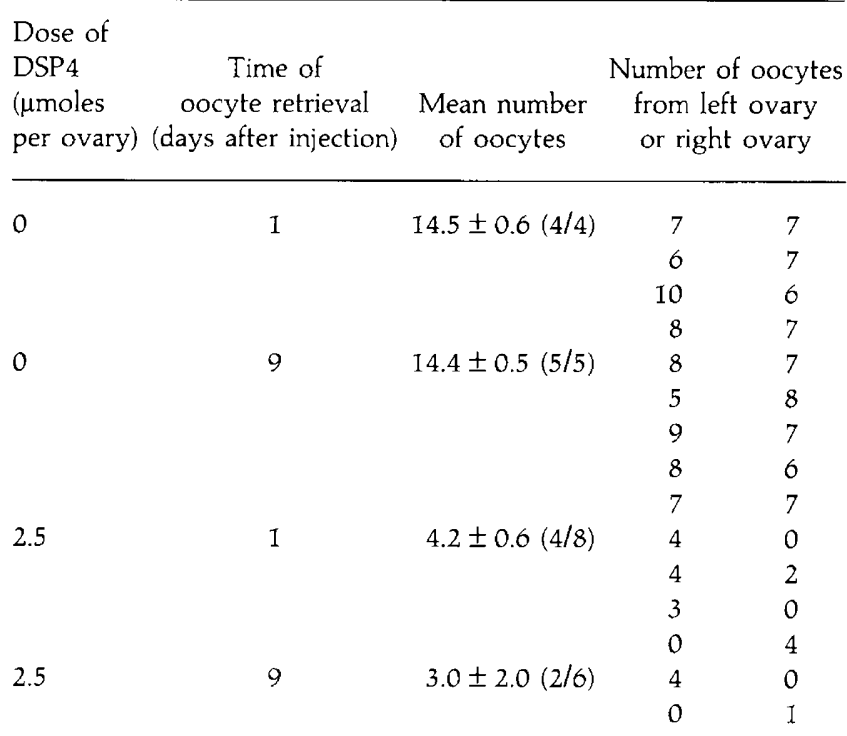

Mean numbers of oocytes ( \pm SEM) represent only ovaries showing evidence of ovulation. The numbers in parentheses represent the number of rats ovulating divided by the total number of rats within that group displaying 4 day cycles after treatment.

alterations for a non-injected side following intrabursal administration (Reich et al., 1983). While the effect could be attributable to the direct escape of DSP4 from the bursal space into the 
Table 4. Effects of desipramine on the suppression by DSP4 of ovarian noradrenaline and oocyte release in rats

\begin{tabular}{|c|c|c|c|c|}
\hline \multirow[b]{2}{*}{ Treatment $^{\mathrm{a}}$} & \multicolumn{2}{|c|}{$\begin{array}{l}\text { Ovarian noradrenaline } \\
\text { (ng } \mathrm{mg}^{-1} \text { protein) }\end{array}$} & \multicolumn{2}{|c|}{ Number of oocytes } \\
\hline & Injected ovary & Non-injected ovary & Injected ovary & Non-injected ovary \\
\hline Control & $3.79 \pm 0.40$ & $3.93 \pm 0.66$ & $6.7 \pm 0.7 \quad(6 / 6)$ & $7.5 \pm 0.5 \quad(6 / 6)$ \\
\hline DSP4 (1.25 $\mu$ moles per ovary) & $0.86 \pm 0.08^{* *}$ & $2.19 \pm 0.20^{* *}$ & $2.8 \pm 1.2 * *(5 / 10)$ & $6.8 \pm 0.4(10 / 10)$ \\
\hline Desipramine + $1.25 \mu$ moles DSP4 & $2.28 \pm 0.23^{* * \dagger}$ & $2.72 \pm 0.20^{*}$ & $2.7 \pm 1.2 * *(7 / 8)$ & $7.1 \pm 0.7 \quad(8 / 8)$ \\
\hline DSP4 (10 $\mu$ moles per ovary) & $0.89 \pm 0.19 * *$ & $0.92 \pm 0.16^{* *}$ & $-\quad(0 / 6)$ & $7.8 \pm 1.4 \quad(6 / 6)$ \\
\hline Desipramine $+10 \mu$ moles DSP4 & $1.67 \pm 0.19^{* *}$ & $3.06 \pm 0.36^{\dagger}$ & $(1 / 6)$ & $6.3 \pm 0.7 \quad(6 / 6)$ \\
\hline
\end{tabular}

a Intrabursal injections of DSP4 or water vehicle were given at 19:00 h on pro-oestrus. Desipramine $\left(20 \mathrm{mg} \mathrm{kg}^{-1}\right.$ i.p. $)$ was administered $\mathrm{I} \mathrm{h}$ earlier. All rats were examined for evidence of ovulation $19 \mathrm{~h}$ later on the day of oestrus. In the DSP4 groups not receiving desipramine, i.p. saline-pretreated animals given subsequent intrabursal DSP4 were combined with animals receiving DSP4 only. $n=6-10$ animals per group. The numbers in parentheses indicate the number of ovaries showing evidence of ovulation divided by the total number examined in that group. ${ }^{*} P<0.05,{ }^{* *} P<0.01$ compared with controls for that ovary. ${ }^{\dagger} P<0.01$ when compared to DSP4-injected ovary for that dose.

Table 5. Influence on ovulation of intrabursal co-injections of DSP4 and naloxone in rats

\begin{tabular}{|c|c|c|c|}
\hline \multirow{2}{*}{$\begin{array}{l}\text { Treatment }^{\mathrm{a}} \\
\text { (dose per ovary) }\end{array}$} & \multirow{2}{*}{$\begin{array}{l}\text { Injected ovaries ovulating/ } \\
\text { total animals treated }\end{array}$} & \multicolumn{2}{|c|}{ Mean number of oocytes released ( \pm SEM) } \\
\hline & & Injected ovary ${ }^{b}$ & Non-injected ovary \\
\hline $2.5 \mu$ moles DSP 4 & $3 / 6$ & $2.0 \pm 1.2^{\dagger \ddagger}$ & $7.2 \pm 0.5$ \\
\hline $\begin{array}{l}2.5 \mu \text { moles DSP } 4 \text { plus } \\
8 \mu \text { moles naloxone }\end{array}$ & $2 / 6^{*}$ & $2.0 \pm 1.4^{\dagger \ddagger}$ & $7.3 \pm 0.9$ \\
\hline $8 \mu$ moles naloxone & $6 / 6$ & $8.0 \pm 1.1$ & $8.3 \pm 1.0$ \\
\hline
\end{tabular}

\footnotetext{
${ }^{\mathrm{a}} \mathrm{All}$ animals were injected at 19:00 $\mathrm{h}$ on the day of pro-oestrus and examined on the following day (13:00-14:00 $\mathrm{h}$ ) for evidence of ovulation. ${ }^{b}$ Group numbers of oocytes for the injected ovary represent means for ovulating ovaries only. ${ }^{*} P<0.05$ for comparison to ovulation frequency of naloxone-injected ovary. ${ }^{\dagger} P<0.01$ for difference between injected and non-injected ovaries within treatment group. ${ }^{\ddagger} P<0.01$ for comparison with mean oocyte number of naloxone-injected ovary.
}

circulation, the bursal foramen (thought to be functionally sealed before ovulation in rats (Alden, 1942)) may allow the i.p. passage of more material than was previously suspected. However, regardless of the route, the results clearly indicate that, in rats, the contralateral ovary should not be used as a control. The dose-related patterns of noradrenaline decline in the individual ovaries did, however, allow informative comparisons to be made between the amounts of noradrenaline depletion and the incidence of ovulation on each side, relationships explored in Expt 2.

While the presence of ovarian noradrenaline has been known for some time, a local noradrenergic role in ovulation has been the subject of some debate. Ovarian noradrenaline changes during the oestrous cycle (Bahr and Ben-Jonathan, 1981; Arbogast et al., 1987), suggesting a local functional role. There is an abundant neuronal supply to the theca externa of follicles, and a few fibres (possibly perivascular in nature) have been detected in the theca interna and corpora lutea (Stefenson et al., 1981; Sporrong et al., 1985); the luteal fibres are probably perivascular in nature. It is also reasonable that secreted noradrenaline reaches more interior regions of the follicle via diffusion through the basement membrane.

There has been some speculation that secretion of noradrenaline within the follicular wall, triggered by the $\mathrm{LH}$ surge, causes an increase in capillary permeability before ovulation (Dmowski, 1990), or that such release may be involved in the ovulatory contraction of the smooth muscle of the wall (Walles et al., 1986). Kannisto et al. (1985) observed that administration of noradrenaline or the $\beta_{2}$-receptor agonist terbutaline to gonadotrophin-primed, immature rats increased the number of corpora lutea, which was used as an index of ovulation. In addition, bilateral intrabursal injections of the $\alpha$-adrenergic receptor antagonists phenoxybenzamine (Walles et al., 1977) or phentolamine (Kannisto et al., 1985) reduced the number of corpora lutea in similarly primed immature females. Intrabursal DSP4, on the other hand, caused no alterations in the number of corpora lutea (J. M. Goldman, M. B. Parrish and T. E. Stoker, unpublished data), even though the number of oviductal oocytes was reduced, implying the formation of luteinized, unruptured follicles on the injected side. Other research has shown that transection of the superior ovarian nerve with its large bundle of noradrenergic fibres caused a marked decrease in ovarian noradrenaline, but failed to alter first ovulation in young rats (Aguado and Ojeda, 1984).

Differences in the nature of the pharmacological/surgical treatment, and age and cyclic status of the animals and the endpoint measures taken make it difficult to reconcile the 
difference in the above findings with those in the current study. Nevertheless, the present data indicate that while intrabursal administration of DSP 4 can induce a persistent ovulatory suppression, the effect is not directly associated with depletion in noradrenaline concentrations. A comparable pattern of noradrenaline decrease in the contralateral ovary was not followed by any detectable effects on the percentage of ovaries presenting evidence of ovulation or on the number of oocytes released. Prevention of the considerable depletion of noradrenaline by prior injections of desipramine did not significantly alter the block to ovulation. In addition, no alterations in the DSP4-induced suppression of ovulation were detected following intrabursal co-administration of the opiate receptor antagonist naloxone, in spite of reports that at least some effects of DSP4 may be attributable to such receptor binding (Jacobson et al., 1985; Wilkinson et al., 1985).

The discrepancy between oocyte release from the injected and non-injected ovaries, coincident with a comparable depletion in noradrenaline concentrations may indicate a distinction between the influence of DSP4 on metabolism of noradrenaline (in both ovaries) and some effect on noradrenergic input (of greater impact at the site of injection). This had previously been suggested to explain similar disparities between noradrenaline concentrations and DSP4 toxicity in the central nervous system (Gibson, 1987). One possibility is that the ovarian neurotoxic effects of DSP4 at the site of injection involve an immune-mediated mechanism, something that has been described for guanethidine noradrenergic neurotoxicity (Manning et al., 1983). Whether some compound-induced cytotoxic alterations did in fact occur over the 6-10 h between injection and the time that ovulation typically would have taken place is not known, although routine histological evaluation of the ovaries $19 \mathrm{~h}$ after intrabursal administration failed to reveal any indication of follicular cytotoxicity (data not shown). Whatever mechanism is involved, the effect appears to be persistent, and the degree of ovulatory suppression was the same for each injection condition studied (that is, $10 \mu$ moles unilateral or $2.5 \mu$ moles bilateral), regardless of whether ovulation was evaluated on the ensuing oestrus or two cycles later.

It appears, therefore, that the observed ovulatory effects in response to DSP4 or its aziridinium derivative are attributable to as yet undefined forms of pharmacological treatment. Conversely, the results indicate that alterations in the concentration of ovarian noradrenaline, in response to a noradrenergic toxicant, do not necessarily provide an accurate reflection of the impact of the treatment on the functional integrity of the ovulatory process.

The authors express their thanks to J. Hein (Health Effects Research Laboratory, US EPA) for her expert technical contributions and to $\mathrm{H}$. Harrell and B. Proctor (PRI/Dyncorp Inc.) for providing animal husbandry support and assistance with the evaluations of ovarian cyclicity. The research described in this article has been reviewed by the National Health and Environmental Effects Research Laboratory, US Environmental Protection Agency and approved for publication. Approval does not signify that the contents necessarily reflect the views and policies of the Agency, nor does mention of trade names or commercial products constitute endorsement or recommendation for use.

\section{References}

Aguado LI and Ojeda SR (1984) Prepubertal ovarian function is finely regulated by direct adrenergic influence. Role of noradrenergic innervation Endocrinology 114 1845-1853

Alden RH (1942) The periovarial sac in the albino rat Anatomical Record 83 $421-433$

Arbogast LA, Garris PA, Rhoades TA and Ben-Jonathan N (1987) Changes in ovarian norepinephrine synthesis throughout the follicular and luteal phases Biology of Reproduction $36899-906$

Bahr JM and Ben-Jonathan N (1981) Preovulatory depletion of ovarian catecholamines in the rat Endocrinology 108 1815-1820

Bicsak TA, Ling N and DePaolo LV (1991) Ovarian intrabursal administration of insulin-like growth factor-binding protein inhibits follicle rupture in gonadotropin-treated immature female rats Biology of Reproduction $\mathbf{4 4}$ 599-603

Curry TE, Jr, Lawrence IE, Jr and Burden HW (1984) Ovarian sympathectomy in the guinea pig. II. Effects on follicular development during the prepubertal period and following exogenous gonadotropin stimulation Cell and Tissue Research $236593-596$

Dmowski WP (1990) Luf, biochemical and clinical advances. In Major Advances in Human Female Reproduction (Serono Symposium 73) pp 235-242 Eds EY Adashi, S Mancuso, A Caruso, AM Fulghesu and A Lanzone. Raven Press, New York

Douglass J, Cox B, Quinn B, Civelli O and Herbert E (1987) Expression of the prodynorphin gene in male and female mammalian reproductive tissues Endocrinology 120 707-713

Dudley MW, Howard BD and Cho AK (1990) The interaction of the betahaloethyl benzylamines, xylamine, and DSP-4 with catecholaminergic neurons Annual Review of Pharmacology and Toxicology 30 387-403

Everett JW and Sawyer CH (1950) A 24-hour periodicity in the 'LH-release apparatus' of female rats, disclosed by barbiturate sedation Endocrinology 47 198-218

Flores A, Ayala ME and Dominguez R (1990) Does noradrenergic peripheral innervation have a different role in the regulation of ovulation in the pubertal and the adult rat? Medical Science Research 18 817-818

Gibson CJ (1987) Inhibition of MAO B, but not MAO A, blocks DSP-4 toxicity on central NE neurons European Journal of Pharmacology 141 135-138

Goldman JM and Cooper RL (1993) Assessment of toxicant-induced alterations in the luteinizing hormone control of ovulation in the rat. In Female Reproductive Toxicology (Methods in Toxicology Vol. 3B) pp 79-9I Eds II Heindel and RE Chapin. Academic Press, San Diego, CA

Goldman JM, Stoker TE, Cooper RL, McElroy WK and Hein JF (1994) Blockade of ovulation in the rat by the fungicide sodium $N$-methyldithiocarbamate: relationship between effects on the luteinizing hormone surge and alterations in hypothalamic catecholamines Neurotoxicology and Teratology 16 257-268

Grzanna R, Berger U, Fritschy J-M and Geffard M (1989) Acute action of DSP-4 on central norepinephrine axons: biochemical and immunohistochemical evidence for differential effects Journal of Histochemistry and Cytochemistry 37 1435-1442

Jacobowitz D and Wallach EE (1967) Histochemical and chemical studies of autonomic innervation of the ovary Endocrinology 81 1132-1139

Jacobson W, Wilkinson M and Gibson CJ (1985) Direct effects of the adrenergic neurotoxin DSP4 on central opiate receptors: implication for neuroendocrine studies Experimental Brain Research 59 570-574

Jonsson G, Hallman H, Ponzio F and Ross S (1981) DSP4 (N-(2-chloroethyl)- $N$ ethyl-2-bromobenzylamine) - a useful denervation tool for central and peripheral noradrenaline neurons European Journal of Pharmacology $\mathbf{7 2}$ 173-188

Jonsson G, Hallman H and Sundstrom E (1982) Effects of the noradrenaline neurotoxin DSP4 on the postnatal development of central noradrenaline neurons in the rat Neuroscience 7 2895-2907

Kalra SP and McCann SM (1974) Effects of drugs modifying catecholamine synthesis on plasma LH and ovulation in the rat Neuroendocrinology $\mathbf{1 5}$ $79-91$

Kannisto P, Owman Ch and Walles B (1985) Involvement of local adrenergic receptors in the process of ovulation in gonadotropin-primed immature rats Journal of Reproduction and Fertility 75 357-362 
Lara HE, McDonald JK, Ahmed CE and Ojeda SR (1990) Guanethidine-mediated destruction of ovarian sympathetic nerves disrupts ovarian development and function in rats Endocrinology 127 2199-2209

Lolait SJ, Autelitano DJ, Lim ATW, Smith AI, Toh BH and Funder JW (1985) Ovarian immunoreactive $\beta$-endorphin and estrous cycle in the rat Endocrinology 117 I61-168

Lookingland KJ, Chapin DS, McKay DW and Moore KE (1986) Comparative effects of the neurotoxins $N$-chloroethyl- $N$-ethyl-2-bromobenzylamine hydrochloride (DSP4) and 6-hydroxydopamine on hypothalamic noradrenergic, dopaminergic and 5-hydroxytryptaminergic neurons in the male rat Brain Research 365 228-234

Manning PT, Powers CW, Schmidt RE and Johnson EM, Jr (1983) Guanethidineinduced destruction of peripheral sympathetic neurons occurs by an immune-mediated mechanism Journal of Neuroscience 3 714-724

Perreault SD and Mattson BA (1993) Recovery and morphological evaluation of oocytes, zygotes and preimplantation embryos. In Female Reproductive Toxicology (Methods in Toxicology Vol. 3B) pp 110-127 Eds JJ Heindel and RE Chapin. Academic Press, San Diego, CA

Plas-Roser S, Kauffmann MT and Aron C (1985) Prostaglandins involvement in the formation of luteinized unruptured follicles in the cyclic female rat Prostaglandins $29243-253$

Reich R, Kohen F, Naor Z and Tsafriri A (1983) Possible involvement of lipoxygenase products of arachidonic acid pathway in ovulation Prostaglandins $261011-1020$

Ross SB (1973) Cyclizing compounds. I. Tertiary $N$-(2-bromobenzyl)- $N$ haloalkylamines with adrenergic blocking action Acta Pharmacologica Suecica $1029-42$

Ross SB (1976) Long-term effects of $N$-2-chloroethyl- $N$-ethyl-2-bromobenzylamine hydrochloride on noradrenergic neurones in the rat brain and heart British Journal of Pharmacology 58 521-527
Smith PK, Krohn RI, Hermanson GT, Mallia AK, Gartner FH, Provenzano MD, Fujimoto EK, Goeke NM, Olson Bj and Klenk DC (1985) Measurement of protein using bicinchoninic acid Analytical Biochemistry $15076-85$

Sporrong B, Kannisto P, Owman Ch, Sjoberg N-O and Walles B (1985) Histochemistry and ultrastructure of adrenergic and acetylcholinesterasecontaining nerves supplying follicles and endocrine cells in the guinea-pig ovary Cell and Tissue Research 240 505-511

Stefenson A, Owman Ch, Sjoberg N-O, Sporrong B and Walles B (1981) Comparative study of the autonomic innervation of the mammalian ovary, with particular regard to the follicular system Cell and Tissue Research $\mathbf{2 1 5}$ $47-62$

Viggiano M, Franchi AM, Zicari JL, Rettori V, Gimeno MA, Kozlowski GP and Gimeno AL (1989) The involvement of oxytocin in ovulation and in the outputs of cyclo-oxygenase and 5-lipoxygenase products from isolated rat ovaries Prostaglandins 37 367-376

Walles B, Edvinsson L, Owman C, Sjoberg N-O, Sporrong B and Stefenson A (1977) Influence of sympathetic nerves, amine receptors and anti-adrenergic drugs on follicular contractility and ovulation Acta Physiologica Scandinavica Supplementum 452 113-120

Walles B, Owman C, Schmidt G and Sjoberg N-O (1986) Evidence for a role of prostaglandins in the adrenergic neuromuscular mechanism of the ovarian follicular wall Neuroendocrinology 43 18-23

Wilkinson M, Jacobson $W$ and Wilkinson DA (1985) The noradrenergic neurotoxins DSP4 and xylamine bind to opiate receptors Brain Research Bulletin 14 493-495

Zaczek R, Fritschy J-M, Culp S, De Souza EB and Grzanna R (1990) Differential effects of DSP-4 on noradrenaline axons in cerebral cortex and hypothalamus may reflect heterogeneity of noradrenaline uptake sites Brain Research $522308-314$ 